\title{
Una Historia de los Heterodoxos Mexicanos
}

ON Julio Jiménez Rueda, director del Archivo General de la
Nación y antiguo profesor de la Universidad Autónoma de México, pertenece, por una larga y bien depurada labor, a la tradición humanística de su patria, que ha ofrecido al mundo ejemplos tan insignes como el de don Joaquín García Icazbalceta. Hay dos tipos de eruditos: los que tienen sensibilidad literaria y los que son ajenos a las letras. Jiménez Rueda es un maestro de la erudición, con viva y honda sensibilidad, con muy fino gusto, con un admirable sentido de la palabra adecuada.

Ha realizado una tarea investigadora de primera mano y de vastas dimensiones. Ha escrito síntesis históricas de crítica aguda y ponderada (Las Letras en México en el siglo XIX) y monografías ejemplares como su excelente estudio sobre don Juan Ruiz de Alarcón. Este libro, magnífica contribución al tricentenario de la muerte del gran dramaturgo, expresa cumplidamente la alianza del esfuerzo erudito y el arte literario. La crítica renovadora del teatro de Alarcón, que en la memorable conferencia de don Pedro Henríquez Ureña sobre el mexicanismo del poeta (México, 1914) tiene su momento creador inicial, y que en la edición y estudio que lleva a término, en la colección de Clásicos Castellanos, don Alfonso Reyes, el gran humanista, alcanza sus mejores logros, ilumina las bellas páginas del libro de Jiménez Rueda. Hay capítulos que son, por la animación del estilo, por la penetración psicológica. verdaderas creaciones literarias. Así, el de la gran ciudad de México en el siglo xvI 
y los de Salamanca y Sevilla. Pero la brillantez indudable del libro no amengua su exactitud, su precisión histórica. Por eso, decíamos antes, que esta monografía es un ejemplo del concierto de la erudición, la crítica y las buenas letras.

Acaba de publicar el ilustre escritor una obra de grandes perspectivas. Comprende desde el inicio de la colonización de Nueva España hasta la Guerra de Independencia. Es una historia religiosa mirada desde el ángulo de las desviaciones, o de las grandes y absolutas negaciones: en suma, una historia de los heterodoxos mexicanos de la época colonial.

Recuerda el autor en unas fervorosas páginas preliminares la famosa obra de la mocedad de Menéndez y Pelayo. De todos es sabido que el gran erudito creador proyectaba una nueva edición de su libro juvenil, verdadera revelación de su tiempo, que hubiera sido, en realidad, una obra harto distinta de la actual Historia de los heterodoxos españoles. Había cambiado con los años el maestro: comprendía todo lo que había de pasión y de lucha en el libro de su mocedad. El mismo concepto del estilo era diferente: "Cada vez escribiré con la mayor sencillez", decía en el prólogo de la nueva edición. $Y$ un capítulo, uno solo, el preliminar de la antigua historia, se convertía en la edición de 1911 en un volumen de más de quinientas páginas, de caudalosa erudición, en el que el humanista se iniciaba en disciplinas que hasta aquel momento no le habían sido familiares. ¿Qué hubiera sido una nueva historia de los heterodoxos españoles? El mismo impulso juvenil entusiasta, la misma fuerza creadora, los mismos retratos prodigiosos, la misma fe sustantiva y profunda; pero una mayor severidad en el método crítico y en el estilo, una resplandeciente serenidad que sólo se alcanza en la perfecta madurez.

E1 libro de Jiménez Rueda aprovecha una fuente documental de extraordinaria importancia: el ramo inquisitorial del Archivo General de la Nación. Varios volúmenes de documentos que tienen esa procedencia ha publicado el gran Archivo, que ha tenido la fortuna de contar como directores a historiadores eminentes, a hombres de buena formación humanística; ayer a don Luis González Obregón, el maestro de los colonialistas mexicanos; hoy, a don Julio Jiménez Rueda.

El momento inicial de la colonización de nuestra América es, en España, de honda inquietud espiritual; la producida por las ideas renacentistas, que traen un nuevo concepto de la vida y del hombre. 
Un maestro de historiadores, el insigne medievalista don Claudio Sánchez Albornoz, en una conferencia muy sugestiva, La Edad Media y la empresa de América, ha estudiado, sin embargo, los factores medievales en la gran aventura del Descubrimiento y la Conquista. $\mathrm{Si}$ a la empresa se le quita su espíritu religioso, su aliento ecuménico, no llegaremos a comprenderla nunca.

Por otra parte, la colonización de América coincide con las grandes luchas religiosas de Europa. "El mundo se ha dividido en dos. España defiende el dogma de la libertad humana y de la responsabilidad moral, frente a la predestinación que inscriben los calvinistas en su programa y al poder decisivo que para los protestantes tiene la fe." (Repito palabras de Jiménez Rueda que aparecen en la introducción.)

Las nuevas corrientes religiosas no encuentran campo propicio en el México virreinal. El protestantismo tiene allí, como en la nación colonizadora, un ambiente de absoluta hostilidad. Las heterodoxias han de venir por otro camino: por el de la persistencia del culto de las primitivas religiones, por el de los iluminados o alumbrados (recuérdese el episodio de los alumbrados de Llerena, la villa de Extremadura, grupo que ofrece puntos de contacto con la doctrina del aniquilamiento, la absoluta quietud que encuentra en el Nirvana su expresión más típica); por el del judaísmo, que en algunos aparentes conversos, siguió manifestándose con una asombrosa fidelidad al viejo culto de sus mayores...

E1 autor reconoce que cualquier capítulo de su obra histórica podría fácilmente convertirse en un libro. El sólo hace "una labor de iniciación". De fecunda iniciación, de amplio y generoso espíritu, añadimos nosotros.

Es, así, el libro de Jiménez Rueda de muy vario y rico contenido ideológico. Examinaremos algunos hechos típicos de esta Historia, de segura erudición, de excelente estilo, de crítica severa y precisa. Un libro que es digno de la alta tradición historiográfica de México.

El libro de don Julio Jiménez Rueda resume con precisión los grandes movimientos religiosos en Europa y su repercusión en América. El autor aprovecha un copioso repertorio documental, en parte 
inédito, en lo que respecta à las heterodoxias del México virreinal, pero antes ilustra el cuadro histórico con referencias indispensables a las corrientes ideológicas europeas.

El erasmismo y la política imperial de Carlos V son los temas de los capítulos iv y v, que evidencian en el ilustre investigador su visión universal y su admirable formación humanista.

Erasmo, el humanista de Rotterđam, alcanza en América una amplia difusión. Pedro Henríquez Ureña, el maestro de la filología, la avalora en su estudio erasmista en el Nuevo Mundo. El autor del Elogio de la locura fué quizás la más grande influencia de su tiempo, en el mundo de las ideas, en un momento de profunda crisis en la cristiandad. Un historiador de la literatura, don Angel Valbuena Prat, ha caracterizado la posición de Erasmo con estas palabras: "Carlos V era amigo de Erasmo, el Papa también, Lutero no lo fué menos. En un momento se esperó que brotara de labios del gran humanista la palabra que viniera a solucionar el grave conflicto que se había planteado para la cristiandad y evitara la división del mundo en dos grandes porciones irreconciliables e incompatibles por las doctrinas que profesaban. Erasmo no pronunció esa palabra y la gran catástrofe sobrevino."

Durante cincuenta años se leyeron profusamente en México los libros del gran renacentista. Hasta 1573 no se consideró que debía prohibirse su lectura; de esta fecha es la orden, en ese sentido, del inquisidor Alonso Fernández de Bonilla. $\mathrm{Y}$ en Nueva España se consideró sospechosos de erasmismo a personajes de no menor cuenta que fray Juan de Zumárraga, el insigne franciscano que fué el primer obispo, en orden cronológico, de México. Su Doctrina breve (año 1544) y la Doctrina cristiana (1545) "son dos libros de inspiración erasmista". La Doctrina compuesta en romance, fué censurada y prohibida por el Arzobispo de México fray Alonso de Montúfar, sucesor de Zumárraga en la silla arzobispal. Con Montúfar se. reunieron en 3 de noviembre de 1559 los padres Diego de Osorio, prior del monasterio de Santo Domingo, fray Domingo de la Cruz y fray Bartolomé de Ledesma, teólogos, y los juristas don Luis de Anguis y el licenciado Orbaneja, y acordaron considerar herética la proposición de la página cinco de la Doctrina, en la que al hablar de las uniones de la Santa Resurrección de Cristo, se afirma que la sangre derramada "fué recogida por la potencia Divinal, a lo menos la que era necesaria para el cuerpo, y fué unida a la Divinidad". Esta afir- 
mación fué tenida por escandalosa y el dictamen sirvió de base para la prohibición que se mantuvo hasta que el Papa Gregorio XIII, por Breve de 1573, autorizó la lectura y la circulación de la Doctrina.

Pedro Henríquez Ureña cree que el Consejo de la Inquisición en España nunca encontró cosa que tachar en la Doctrina de Zumárraga, que transcribe, retocándolos, pasajes del Enquiridión y la Paráclesis de Erasmo.

Fray Juan de Zumárraga, que tiene ya una biografía de valor clásico, el libro de don Joaquín García Icazbalceta, el insigne humanista e investigador mexicano, es, sin duda, uno de los grandes nombres de la Iglesia en América. Del humilde y apostólico franciscano hay, entre otros documentos de valor excepcional, una carta al emperador Carlos $\mathrm{V}$, que considero como la expresión más genuina de la obra misionera en las Indias. La escribe el obispo el 4 de octubre de 1534. Expone al Emperador lo que considera más conveniente para el gobierno espiritual y temporal de la Nueva España, y dice entonces estas palabras: "Muchos años ha que se tiene por presupuesto la mucha necesidad que esta tierra tiene de los españoles, y es tanta cuanto en el cuerpo humano la carne tiene de los huesos para ser sustentada y los huesos de la carne para ser cubiertos y refocilados por ella. Los españoles nos parecen ser los huesos, pues son la fortaleza de la tierra, y los indios son como la carne... Entre éstos se seguirá gran atadura y vínculo de amor, en el cual consiste todo el bien de la Iglesia, así en lo espiritual como en lo temporal, y bienaventurado será el que amase estos dos pueblos en este vínculo de amor."

Tal lengua angélica está pregonando su pura ascendencia franciscana; es digna del abrasado Serafín de Asís. Sólo el vínculo de amor puede hacer fecunda, puede dar un sentido de perdurabilidad a la obra de los hombres. Recordemos las palabras de Zumárraga en este Domingo de Resurrección de 1946 en que vemos tantas cosas en el mundo que necesitan de este vínculo de amor, de ese espíritu que no es otro que el de la caridad cristiana, tal como lo vemos resplandecer en la imperecedera Epístola de San Pablo.

De importancia puramente episódica pueden calificarse las tentativas protestantes en México. El autor las relata en el capitulo sexto de su historia, dedicando preferente atención a la figura de John Hawkins, el compañero de Drake, el famoso marino. 
Mucho mayor relieve alcanza el judaísmo en España. Hay una familia, la de don Luis de Carvajal, el viejo, gobernador y capitán general del Nuevo Reino de León, que sintetiza el fuerte espíritu de los descendientes de los judios expulsados del tiempo de doña Isabel la Católica. La investigación histórica ha trabajado con fecundo resultado en ese tema, de inexhausto interés humano. Don Alfonso Toro, maestro en tales disciplinas, tiene un excelente libro en dos tomos nutridísimos, con este título: La familia Carvajal (México, 1944). La vasta documentación del Archivo General de la Nación relativa al juicio seguido por el Santo Oficio de México, contra el célebre gobernador, lleva este rubro: "Proceso contra Luis de Carvajal, Gobernador del Nuevo Reino de León, natural de la Villa de Mogodorio, en el Reino y Raya de Portugal, cerca de Benavente, estante en México de generación de cristianos nuevos judios, sospechosos en la ley de Moisén en que le quisieron enseñar y convertir."

Su prisión se efectúa el 13 de abril de 1589. Refiere Jiménez Rueda que por todo caudal le encontraron tres reales. " $i E 1$, que había sido uno de los hombres más ricos y poderosos de la Nueva España?"

En el complicadísimo proceso aparece en menor o mayor conexión con los hechos imputados toda la familia del gobernador, sin exceptuar su sobrino don Gaspar de Carvajal, fraile de la Orden de Santo Domingo. (En el "enojoso asunto" no abandonan a éste sus hermanos de la Orden de Predicadores. En lugar de los calabozos del Santo Oficio, su propio convento le sirvió de cárcel. Y al fin sale del proceso, libre de culpa.)

El gobernador, que había sido verdadero poblador de la región encomendada a su pericia, salió relativamente bien en la sentencia, dada la calidad de los enemigos que se habían propuesto perderle. Fué condenado a excomunión mayor y a que oyera la sentencia con hábito de penitente, "estando con una vela de cera en la mano", y a ser desterrado por seis años. Pero como tenía pendiente otro proceso de orden criminal por la justicia del Virrey, nunca salió de la cárcel. Sus muchas penalidades precipitaron su fin. No llegó así a ver la segunda parte del drama de su familia, de la que es verdadero protagonista don Luis de Carvajal, el mozo; un judío converso en el que alientan un hondo mesianismo y un indudable espíritu de poesía, lleno de acento místico, de sentido vaticinador, profético.

Pero este personaje singular merece capítulo aparte. 
El primero de febrero de 1595 Luis de Carvajal, el mozo, sobrino y homónimo del antiguo gobernador del Nuevo Reino de León, fué denunciado por el fiscal del Santo Oficio porque, siendo reconciliado, "había vuelto a guardar la ley de Moisés y le había enseñado a otras personas". En la noche de ese mismo día fué conducido a las cárceles secretas. Le decomisaron tres libros pequeños, encuadernados en cuero negro y escritos en latín, titulados Salmorum, Propheteo y Génesis.

El insigne humanista don A. Méndez Plancarte, autor de una preciosa monografía sobre Horacio en México, en su antología Poetas novohispanos (1521-1621) recoge distintos salmos "castizos y parcialmente romanceados y que añaden a su desnuda sinceridad el interés de una nueva influencia del lirismo de Israel en nuestra poesía primitiva". Hubo, así, en la tradición oral de los judíos conversos de México una poesía religiosa de penetrante fervor y que tenía su punto de partida en los majestuosos himnos del Rey Profeta. He aquí una muestra de este género de poesia:

\footnotetext{
No me dejes, Señor, en este trance, ni te apartes de mí, consuelo mío. ¿Quién, si me dejas, te dará un alcance? ¿quién templará mi loco desvario?

Buscando voy mi bien de lance en lance, mas hállome sin fuerzas y $\sin$ brío; ayúdame, Señor, que estoy sin calma, no dejes sin salud mi vida y mi alma.
}

Ese Salmorum que encontraron a don Luis de Carvajal, debía contener variantes de esta poesía, desde luego en lengua latina.

Habían pasado para no volver aquellos tiempos en los que una gran figura de la mística española, el iluminado doctor Raimundo Lulio, a quien la Iglesia como beato rinde culto en los altares, escribía un libro que quizá sea el testimonio más alto de tolerancia que registra la historia de la cultura: El libro del gentil y los tres sabios. No sé por qué no se hace una edición popular de esta obra luliana, transida de emoción poética, de profundo acento religioso $y$ de una desbordada humanidad. Recordemos las líneas generales 
de su argumento. Un gentil, que ha perdido la fe en sus antiguos dioses, encuentra en su camino a tres sabios: un hebreo, un cristiano y un musulmán. Los tres comprenden la desolación de aquella alma. Los tres coinciden en estas verdades esenciales: la existencia de un solo Dios y la inmortalidad del alma. Entonces. cada uno, y en el orden de antigüedad de su Ley, expone al gentil los fundamentos de su fe, es decir, habla primero el judío, después el cristiano y, por último, el mahometano; y cuando termina cada uno su exposición, pide perdón a los otros por si en el curso de las pláticas algo ha podido decir que ofendiera sus íntimos sentimientos. $Y$ Lulio, que termina sus días sufriendo martirio por propagar la fe de Cristo, no decide la cuestión de la religión verdadera, sin duda porque no era necesario para una fe tan robusta como la suya.

Luis de Carvajal, el mozo, se mantuvo en el proceso firme en sus convicciones. En las páginas del legajo judicial constan los trece artículos de la Ley que pidió permiso para recitar de rodillas, en el primero de los cuales me parece vislumbrar un pensamiento emanatista, tal como aparece con radiante belleza en un hebreo español de los tiempos medios que alcanzó las cumbres de la poesía mística, Salomón Ben Gabirol, autor de La fuente de la vida, cuya filosofía, al decir de Menéndez y Pelayo, "es la más audaz que ha brotado dentro de la sinagoga y estriba en un emanatismo alejandrino con reminiscencias gnósticas".

Decía este artículo primero: "Creer que el Altísimo Adonay es. de absoluta y perfecta esencia, que todo lo ve, causa y principio de todo lo creado... increado, inmutable y eterno... el más claro de conocer según su sustancia, pero de todos desconocido por su infinito ser, perfecto, beatísimo, principio, medio y término de todo, de quien todo depende en forma y grandeza inenarrable... y creer que de él mana la virtud de tódas las cosas."

Salomón Ben Gabirol, en el fragmento de la "Corona Real" (una de las más largas composiciones de La fuente de la vida) que traduce Menéndez y Pelayo, dice: "Eres sabio, y la sabiduría es la fuente de la vida que brota en Ti. Eres sabio y la sabiduría fué desde la eternidad tu retoño querido. Eres sabio, y de tu sabiduría emanó. tu voluntad de artífice para sacar el ser de la nada. $Y$ a la manera que la luz se difunde en infinitos rayos por todo lo creado, así manan eternamente las aguas de la fuente de la vida, sin que su caudal se agote, sin que Tú necesites instrumentos para tus obras." (Menén- 
dez y Pelayo: De la poesia mistica. Discurso de recepción en la Academia Española.)

En el retrato que Jiménez Rueda traza con líneas vigorosas, José Lumbroso, que es el nombre que Luis de Carvajal adopta después de sueños reveladores, aparece como poseído del espíritu mesiánico de su raza. Esto explica que aun siendo extremadamente sensible al dolor físico, se mantuviera firme hasta el momento final, en. la fe religiosa de sus mayores.

En un pliego que el mismo procesado entrega a sus jueces hay un soneto "que tiene el sabor de los mejores versos religiosos de la época":

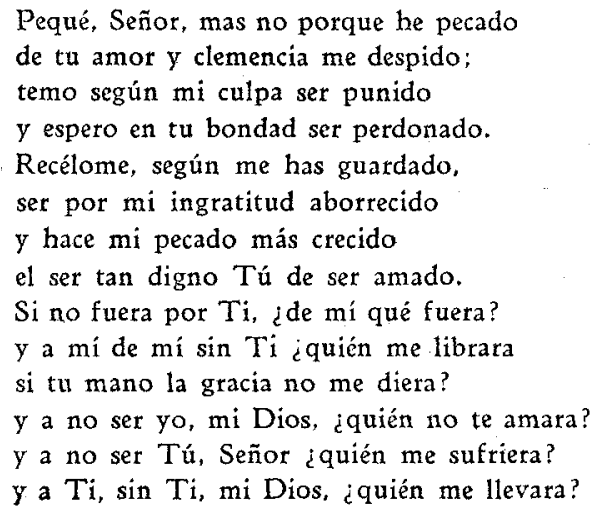

Con don Luis de Carvajal estaban en la prisión su madre y sus hermanas. Por medios muy ingeniosos les dirige el joven hebreo mensajes que no pueden leerse sin emoción. Como dice don Julio Jiménez Rueda, no en vano vivió José Lumbroso en el siglo que había visto nacer y morir a Santa Teresa y a San Juan de la Cruz. Esta es la lengua en que contaba a los suyos don Luis de Carvajal sus visiones ultraterrenas: "Angel mío, albricias, que mejor viaje es el del Paraíso que el de Castilla, bienaventurado el pan que comiste y el agua que bebiste y la tierra que pisaste... que de aquí a poco hemos de profesar la religión sacra de los ángeles.

“ Oh qué ricos jardines, músicas y fiestas nos esperan! iLindos torneos se han de hacer en el cielo cuando Adonay nos corone para su firme fe!... iQuién pudiera contaros todo lo que el Señor me ha mostrado! Mas con su ayuda presto nos veremos. Tres semanas estuve en el calabozo, ya me sacó Adonay mi Señor y me puso 
donde veo el cielo día y noche. Una Biblia como milagro, tuve ocho días aquí."

Se habrá advertido que Luis de Carvajal, como tantos descendientes de los judíos expulsos de España y Portugal, seguía considerando a Castilla como el país ideal, pues le sirve de término de comparación con el Paraíso: "Mejor viaje es el del Paraíso que el de Castilla." ¡Hondo y melancólico recuerdo que durante siglos y siglos conservará el sefardita!

Termina en la muerte el proceso en el que se percibe tan firme aliento de poesía. En una noche trágica de 1596 "pereció el más atrayente de los heterodoxos mexicanos", para repetir las palabras de Jiménez Rueda. Es una página tristísima, en la que don Luis de Carvajal, el mozo, "aparece como una figura neta, destacada y pura en sus motivos y propósitos".

¡Qué lejos está la prosa animada, de variados contornos, de este libro de investigación histórica, del estilo seco, sin vida y sin alma de tantos eruditos! De tantos eruditos sin estilo, pudiéramos decir.

Muy curiosos y llenos de recónditos detalles son los capítulos dedicados a los iluminados del siglo xvir, a las influencias en Nueva España de la doctrina quietista de la Guía espiritual de Miguel de Molinos. Y ya que mencionamos al quietismo, es de gran interés el documento que publica Jiménez Rueda y que trata de dilucidar" si el célebre soneto "No me mueve, mi Dios, para quererte", atribuido unas veces a Santa Teresa, otras a San Francisco Javier, y que el erudito mexicano don Alberto María Carreño considera como de fray Miguel de Guevara, tiene o no ideas quietistas. En el Dictamen, el calificador del Santo Oficio no acepta la atribución a San Francisco Javier y niega que esta joya de la poesía lírica "tenga sentido heretical".

Termina esta historia en la Guerra de Independencia. Algún personaje como fray Servando Teresa de Mier, de vida tan colmada, tan llena de aventuras y contrastes, pasa demasiado rápidamente por las páginas finales del libro. Verdad es que las principales actividades del fraile famoso discurren en años a los que no llega la obra de Jiménez Rueda ¿Fué jansenista? ¿No pesó esta sospecha también sobre un amigo de fray Servando, que quizá en los anales de la Iglesia en Cuba escribe el más fulgurante capitulo?

Hablamos del más célebre de los obispos en Cuba, don Juan José Días Espada y Landa. Sabemos que muy en breve un joven 
escritor dará a conocer "la causa" del obispo que guardan los Archivos del Vaticano y que termina satisfactoriamente para el gran prelado.

Don Julio Jiménez Rueda no resume en un capítulo final las conclusiones a que llega en este proceso histórico de tres siglos. A mi entender, la primera, la más inmediata, no puede ser otra que la profunda religiosidad de un pueblo, que en sus mismos heterodoxos da ejemplo de inquietud mística y de un hondo fervor espiritual.

El excelente libro de don Julio Jiménez Rueda ${ }^{1}$ es no sólo un gran servicio a la historia de las ideas en México: es también una admirable afirmación de los más puros valores del espíritu.

\section{J. M. Chacón y Calvo, La Habana, Cuba.} México.) Imprenta Universitaria. México, 1946. 
